\title{
Digitalization in the system of methods of scientific knowledge
}

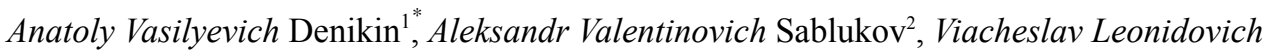 \\ Primakov ${ }^{2}$, Valery Alexandrovich Lapshov ${ }^{2}$ and Pirmagomed Shikhmagomedovich \\ Shikhgafizov ${ }^{3}$
}

${ }^{1}$ Financial University under the Government of the Russian Federation, Department of Humanities, Moscow, Russia

${ }^{2}$ Moscow State Linguistic University, The Department of Social Sciences at the Institute of International Relations and Social and Political Sciences, Moscow, Russia

${ }^{3}$ Financial University under the Government of the Russian Federation, Department of Sociology, Moscow, Russia

\begin{abstract}
The study aims to clarify the methodological status of digitalization in the framework of the philosophical theory of knowledge. The subject of the study: explication of the instrumental and methodological nature of digitalization. The problem is solved by employing the categorical and conceptual apparatus of philosophy of science, particularly in paradigm analysis. A comparative analysis of the concepts of "information" and "digitalization" is carried out. Information within the framework of classical scientific rationality coincides with the phenomenon of absolute-relative knowledge. In non-classical rationality, it represents a movement of meaning and expresses the value-valued nature of information technology. In postnonclassical science, the phenomenon of information is associated with intrasystemic communications. Digitalization as a mode of data transmission is incorporated into the deductive and inductive logic of classical science and leads to an essential limitation of the source base. In modern science, data selection entails the creation of systematic factual meaning, and digitalization coincides with analytical activity. In addition to general logical functions, digitalization points to new perspectives on such types of systems methodology as modeling and design. In relation to the information as a methodology, digitalization acts as a meta-methodology. That is, the digital world is defined as an observing reality. In the framework of digitalization, information is identical to knowledge in its postnonclassical meaning. In digitalization, the process of cognition is incorporated into reality itself, forming an intersubjective field of meaning. In this context, digitalization serves as an inter-paradigmatic method of scientific knowledge. Digitalization refers to the rational side of cognition and is a type of systematic methodology and general logical methods.
\end{abstract}

\footnotetext{
* Corresponding author: andenikin@yandex.ru
} 
Keywords: information, digitalization, information data, data selection, information technology, digital world

\section{Introduction}

The topic of the methodological status of digitalization is very relevant for philosophical, sociological, and interdisciplinary analysis $[1,2]$ and has significant epistemological and practical significance. It is difficult to deny that modern technical and technological innovations need to be understood from the perspective of social knowledge (discussions about the information society, the knowledge society) [3-11] and from the perspective of the philosophical theory of knowledge [12-15]. It is known that scientific knowledge is a developing system of knowledge, including empirical, theoretical, and metatheoretical levels. Collection of facts, their primary generalization, description of observed and experimental data, systematization, and classification are essential features of empirical knowledge. The theoretical level of scientific cognition is characterized by the predominance of the rational moment - concepts, theories, laws, and other forms of thought; the metatheoretical level serves to explain the lower levels. There are "eternal" methodological constants that form the substratum of empirical and theoretical cognition, but in the course of the evolution of modern science, the forms of their expression are transformed.

The initial hypothesis is that digitalization refers to the rational side of cognition and is a type of theoretical and metatheoretical methodology. To understand the logic of this transformation, let us compare the concepts of "information" and "digitalization". In our view, within the framework of classical scientific rationality, information is understood as the process of producing, storing, and transmitting knowledge in order to approach the absolute-relative truth.

Another concept of information is associated with a non-classical type of rationality, the desire for a consensus of heterogeneous discourses. Information is the process of producing, storing, and transmitting meanings. Unlike the phenomenon of knowledge, the meaning has a subjective content and expresses the value-evaluative nature of information technologies. Information becomes a cognitive and practical resource of the subject if communication closes between sender and receiver and meaning is formed. In other words, information is symbolic communication.

In postnonclassical science, the interpretation of information as an intra-system communication is actualized, affecting the degree of system self-organization with decreasing or increasing chaos. It seems that this understanding expresses the need to engage a paradigmatic approach to the methodological tools of epistemology. Broadly speaking, information technology contributes to an effective functional state of social being. At the same time, the scientific literature is increasingly asserting the idea that social life is already saturated with information tools and information products, that the informatization of social space has already taken place. Based on these perceptions, we can talk about the completion of the informatization phase [16].

Today's world is transitioning to a new technological state: digitalization. In a substrate sense, the basic technologies, the carriers of digitalization, are the Internet and mobile communications. Currently, the sociological definition of digitalization prevails in Russian science. Wiktionary defines "digitalization" as "a digital way of communicating, recording, transmitting data using digital devices" [17]. Marey sees digitalization as a paradigm shift in communication and interaction with each other and society [18]. Vartanova, Makseenko, 
Smirnov expand the content of this concept, referring to digitalization as a complex solution of infrastructural, managerial, behavioral, cultural nature [19]. The prerequisites of digitalization include globalization, the development of Internet technologies, the growth of computing power of processors, the ubiquity of mobile devices, and the deep integration of international information networks into the cognitive process [20].

\section{$2 \quad$ Materials and methods}

Let us adopt the concept of digitalization to the conceptual and categorical apparatus of social philosophy and philosophy of science. The fact that digitalization is a way of communicating data indicates the practice-oriented nature of the technology, and the fact that digitalization serves as a way of communicating that data signals the intellectual nature of the technology. The term "data", which dominates definitions of digitalization, is interesting in terms of a family of ontological and epistemological concepts.

First, the data are neutral for the characteristics of empirical and theoretical knowledge. These can be empirical facts, theoretically loaded facts, formalized objects, abstract objects, theoretical constructs, etc. Second, the data are neutral for the subject-object nature of the cognitive process; they equally reflect both subject and object reality. Third, data is ontologically indifferent to objective and virtual reality, both of which act as a source of cognition (online games, social networks, etc.).

Digitalization removes the ontological opposition of finite and infinite reality. Now digitalization includes information resources, information data arrays, "limiting" information infinity (photos, audio, etc.). The deductive and inductive logic of classical science presupposes an essential limitation of the source base. The order of ideas follows the order of things, that is, the essentially finite reality.

\section{$3 \quad$ Results}

In modern science, the evidence base of digitalization is not limited, but data not selected, not digitized, do not make systemic sense, and do not yet become facts. Choice data processing is a methodological technique, a way of limiting an infinite procedural reality. In terms of postnonclassical science, selecting data from the flow of information and searching for relevant content is embedded in the evidence base.

Digitalization coincides with the technical support of a specific analysis procedure; it acts as a type of analytical activity. Digitalization is a kind of mechanism for entering information about the phenomena of reality into the subject's consciousness, providing its processing and certain processing. As an analysis, digitization performs the function of "sorting" the information received by the subject. In this sense, digitalization is a type of general logical method of analysis and synthesis, induction and deduction, because the search and selection of information are carried out under conditions of certainty and uncertainty.

In our view, digitalization should also be classified as a type of systematic methodology. It seems that digitalization has provided new epistemological opportunities for such types of systems methodology as modeling and design [21]. Digitalization acts as a meta-methodology since the information world is an observable reality for digital technology with regard to informatization. The digital world is an observing reality that models the objective world and the world of information data. 


\section{Discussion}

Undoubtedly, digitalization has a targeted practical orientation [5, 22-26]. The effectiveness of this procedure depends largely on the result of the selection operation, the comprehension of the data stream. In this respect, the concepts of "technology" and "method" are related as method and technique. It seems that in the case of digitalization, there is a postnonclassical epistemological effect of "recycling" of theory and method and ontologization of methodology. How the data is connected is the project activity and the reality with which the communication subjects subsequently work. Digitalization is often defined as an instrumental method [26] and as an environment of existence [27].

The epistemological function of digitalization is the discovering of postnonclassical knowledge (not in Popper's sense). In science, Popper adheres to the separation of discovery and the situation of justification $[28,29]$. Discovery means an intuitive, logically not reasoned proposal of a new theory. If a theory is not falsifiable, it tells us nothing about the world, the entire process of scientific cognition is the selection and interpretation of facts.

On the other hand, digitalization implies a logically reasoned offer of information since digitalization constitutes the object of knowledge, arranges knowledge about that object, and determines its practical value. In our view, within the framework of digitalization, information is identical to knowledge in its postnonclassical meaning. Knowledge in any form of intrasystem reflection contributes to the self-organization of the system. In digitalization, traditional methods of scientific knowledge are modified, the system methodology acquires a new sounding.

\section{Conclusion}

Let us summarize. Explicating the phenomenon of digitalization as a method of scientific knowledge expands the categorical apparatus of the description of the object and means of knowledge. An analysis of digitalization as a cognitive parameter reveals the watershed between sociological and philosophical views of this process and, at the same time, indicates points of convergence between them.

Thanks to digitalization, the process of cognition is incorporated into reality. The uniformity achieved in digitalization in the receipt, processing, storage, and use of information is enshrined meaningfully and functionally, forming an intersubjective field of meaning. Digitalization does not reflect a reality independent of the subject; rather, digitalization contributes to a holistic picture of the world, serving a metatheoretical function. The subject of cognition is within reality, which is by no means ephemeral; the selection and processing of information data point to the rational nature of the subject's constructive actions [30].

Digitalization belongs to the rational cognition, theoretical and metatheoretical levels of knowledge, the class of general logical methods, and is a single-order method along with modeling and construction. Digitalization can be effectively applied in classical, non-classical, and postnonclassical types of scientific rationality; that is, digitalization is an inter-paradigm method of scientific cognition. Like any other method, it has undoubted advantages and disadvantages. The task of the subject of cognition, the modern researcher, is to realize the benefits and minimize the negative consequences of the use of digitalization in scientific cognition. 


\section{Acknowledgments}

The article is based on the results of research carried out at the expense of the Scientific Fund of the Financial University under the Government of the Russian Federation. Research work "Strategy of humanitarian education".

\section{References}

1. D.I. Dubrovsky, V.A. Lectorsky, Ot redaktorov [From the editors], in D.I. Dubrovsky and V.A. Lectorsky (eds), Artificial intelligence: an interdisciplinary approach (Moscow, 2006)

2. M. Castells, The End of the Millennium, The Information Age: Economy, Society, and Culture, Vol. III (Cambridge, Oxford, Blackwell, 1998)

3. N. Behmann, Quest Philos, 2, 113-126 (2010)

4. A.A. Chernov, Formirovanie globalnogo informatsionnogo obshchestva: problemy i perspektivy [Formation of the global information society: problems and prospects] (Publishing and Trading Corporation "dAshkov and K.", Moscow, 2003)

5. Osnovnye kontury kontseptsii obshchestva znanii [The main outlines of the concept of the knowledge society], in V.V. Vasilkova, J.A. Verbitskaya (eds), The Society of Knowledge: from idea to practice, in 3 parts. Part 1 (Scythia-print, St. Petersburg, 2008)

6. A. Bardi, S.H. Schwartz, Pers Soc Psychol Bul, 29(10), 1207-1220 (2003)

7. W. Bilsky, M. Janik, S.H. Schwartz, J Cross-Cult Psychol, 42(5), 759-776 (2011)

8. R. Bonney, et al., BioSci, 59(11), 977-984 (2009)

9. K. Esau, Anal Kritik, 40(1), 55-72 (2018)

10. M.A. Ferrario, et al., Software engineering for 'social good': integrating action research, participatory design, and agile development Companion, in Proceedings of the 36th International Conference on Software Engineering - ICSE Companion 2014, 520-523 (2014)

11. K. Kalimeri, et al., Comput Hum Behav, 92, 428-445 (2019)

12. A.V. Aksyukhin, A.V. Vitsen, Zh.V. Meksheneva, Mod High-Tech Techn, 11, 50-52 (2009)

13. V.V. Laptev, Metodologiya vizualizatsii [Visualization methodology] (Mir, Moscow, 2011)

14. V.G. Gorokhov, Epistem Philos Sci, 2, 14-32 (2008)

15. L.V. Skvortsov, Informatsionnaya kultura i integralnye znaniya: Izbrannye raboty [Information Culture and Integral Knowledge: Selected Works] (INION RAS, Moscow, 2001)

16. T.V. Nikulina, E.B. Starchenko, Pedag Edu Rus, 8, 109 (2018)

17. Digitalization. Accessed on: October 14, 2021. [Online]. Available: https://en.wikipedia.org/wiki/Digitization

18. A. Marei, Digitalization as a paradigm shift. Accessed on: October 14, 2021. [Online]. Available: https://www.beg.com/ru-ru/about/beg-review/digitalization.aspx 
19. E.L. Vartanova, et al., Industriya rossiiskikh SMI: tsifrovoe budushchee [The industry of Russian media: the digital future] (MediaMir, Moscow, 2017)

20. V.G. Khalin, G.V. Chernova, Manag Consult, 10, 46-63 (2018)

21. Frank E.V., Mashevskaya O.V. \& Ermolina L.V. (2016). Innovational mechanism of implementation of cluster initiatives in business//European Research Studies Journal. 2016. T. 19.№ 1. P. 179-190

22. A. Kohll, How to build a positive company culture (2018). Accessed on: October 14, 2021. [Online]. Available: https://www.forbes.com/ sites/alankohll/2018/08/14/how-to-build-a-positive-company-culture/\#24410a1849b5

23. J.M. Palma-Oliveira, et al., Risk Anal, 38(3), 620-634 (2017). https://doi.org/10.1111/risa.12860

24. Y. Atif, C. Chou, J Educ Technol Soc, 21, 152-154 (2018)

25. J. Hemerling, D. Dosik, Sh. Rizvi, A Leader's Guide to “Always-On” Transformation (2015). Accessed on: October 14, 2021. [Online]. Available:

https://www.bcg.com/publications/2015/people-organization-leaders-guide-to-always-o n-transformation

26. M.U. Scherer, Harv J, Law Technol, 29, 353-400 (2016)

27. V.I. Panov, E.V. Patrakov, Tsifrovizatsiya informatsionnoi sredy: riski, vospriyatie, vzaimodeistvie [Digitalization of the information environment: risks, perceptions, interactions] (FSBI " Psychological Institute of RAO", Moscow, 2020)

28. K. Popper, Objective Knowledge: An Evolutionary Approach (1979)

29. K. Popper, The Logic of Scientific Discovery (Hutchinson, London, 1959)

30. K. Lorenz, Evolution and Modification of Behaviour (Methuen, London, 1966) 